\title{
Lives outside the map: the case of Angorpota-Dohogram Enclave, Bangladesh
}

\author{
1. M Atiqur Rahman*, ${ }^{2 .}$ Md. Mahbub Murshed ${ }^{3 .}$ Nahid Sultana \\ Department of Geography and Environmental Studies, University of Chittagong, Chittagong-4331, \\ Bangladesh
}

\begin{abstract}
The enclave problem is highlighted mainly as a political problem rather the social, economic and human rights related problems of the enclave people in previous researches. The present study tries to find out the present socio-economic condition and status of government services. Another important focus of the study was to understand the perceptions of the people on exchanging the enclaves between the two countries. Questionnaire survey was the main method of data collection. The study finds that the living standard of the enclave people has improved after the full time access through the Indian corridor to the mainland. Government services like education, medical facilities, electricity and other basic facilities are now expanding. Regarding the exchange of enclaves, the people of Angorpota-Dohogram are united and they are not interested to be the citizen of India whatever their living standard and sufferings and they expect a permanent solution to end their inhuman condition of statelessness.
\end{abstract}

Key words- Angorpota-Dohogram, Bangladesh, Enclave, Exchange, Socio-economic

\section{Introduction}

Enclave or exclave (Chitmahal in Bengali) means a portion of territory of one state surrounded by territory of another or others, as viewed by the surrounded territory [1]. There are a good number of enclaves all around the world, which were created for a variety of historical, political or geographical reasons.

Both Bangladesh and neighboring India are suffering much from enclave problem. There are a total number of 162 territories within Bangladesh and India, which are commonly known as 'Chitmahal' in Bengali which means the land disconnected from the mainland. There are 102 Indian exclaves inside Bangladesh and 71 Bangladeshi ones inside India, with a combined population between 50,000 to 100,000. Inside those enclaves are also 28 counter-enclaves and one counter-counter-enclave. Maximum Indian exclaves are located in the north-west part of Bangladesh in the districts of Lalmonirhat, Panchagarh, Kurigram and Nilphamari. On the other hand, the Bangladeshi exclaves are located in Kuchbihar and Jolpaiguri districts of West Bengal of India [2] [3].

These enclaves are the consequence of the historical partition of Indian subcontinent awarded by Sir Redcliff in 1947 [4]. The imminent territory within these two countries created an inhuman situation for the people of these enclaves. In the Mujib-Indira treaty 1974 of boundary identification between Bangladesh and India, it was mentioned that the people of these enclaves and exclaves might live in any of these two countries [5]. However, the treaty was not finally executed or no effective steps were taken in last 40 years and the enclave people are passing their days in an inhuman situation of statelessness [6].

\section{Study Area}

The present study was conducted within the largest Bangladeshi enclave Angorpota-Dohogram connected with the mainland by a small corridor of India. It lay in the embrace of the mighty and treacherous Tista River, and it almost cut off a portion of Indian Territory (Kuchlibari) from the rest of India (Map-1). 


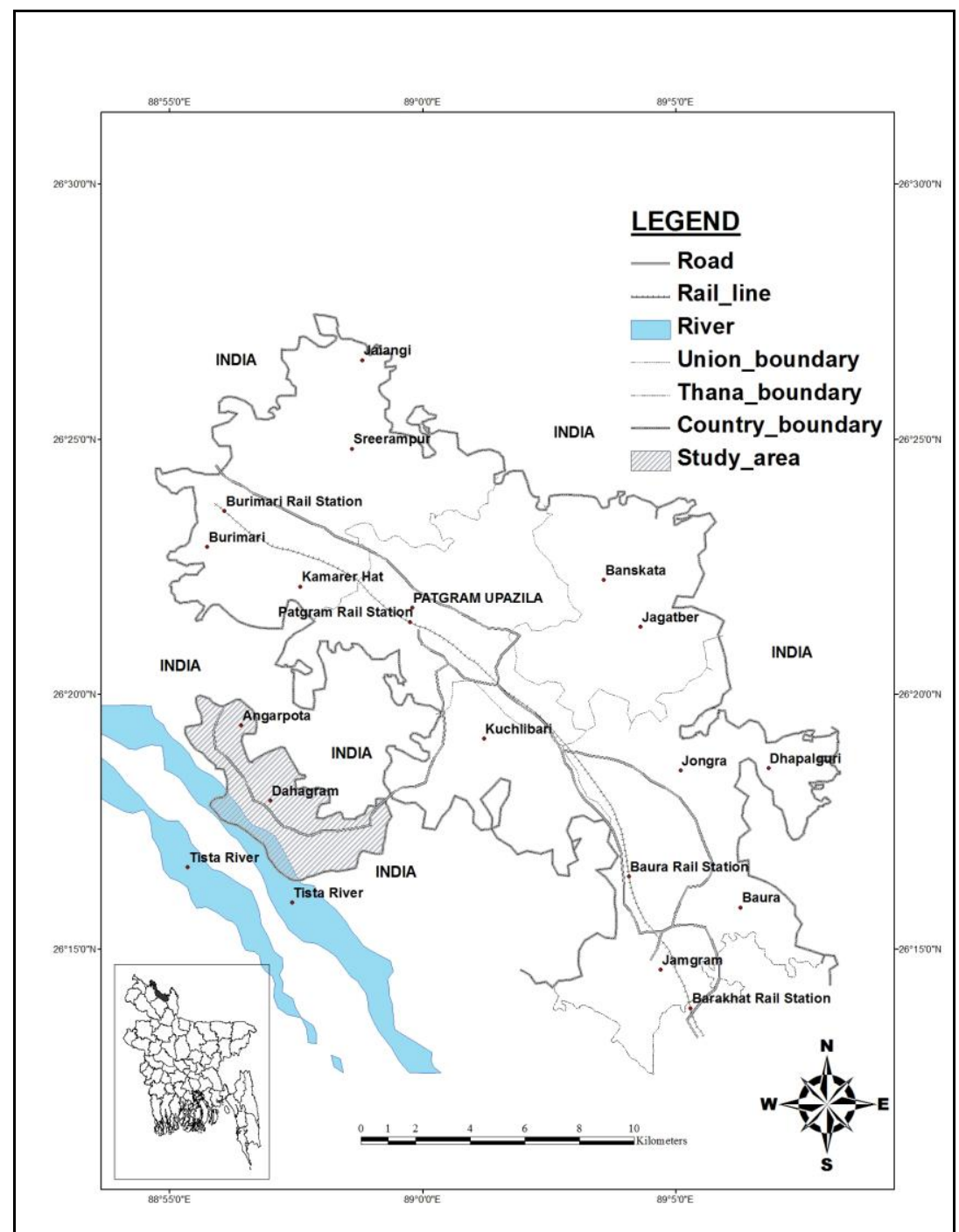

Map 1: Patgram Upazila and Angorpota-Dohogram Enclave

The Angorpota-Dohogram enclave is administrated by Patgram upzila of Lalmonirhat district of Bangladesh and lies within the Indian province of Kuchbihar. The enclave has an area of $25 \mathrm{~km}^{2}(10 \mathrm{sq}$ mi) with a population of 20,000. The Angorpota-Dohogram enclave is connected with the main land of Bangladesh by a strip of land named as 'Tin Bigha Corridor' (Tin is the word for the numeral "three" in Bengali, and bigha is a unit of area ranging from 178 x $85 \mathrm{sq}$ meter) belonging to India on the West Bengal-Bangladesh border. The land was actually leased indefinitely to Bangladesh so that the people could access the Angorpota-Dohogram enclave from the mainland [7].

The corridor was previously opened for 12 daylight hours only causing great hardships for the inhabitants of the enclave, given the fact that the enclave has no hospitals or law enforcement facilities [8] [10]. Following a treaty signed by the Prime Ministers of India and Bangladesh on September 6, 2011 in Dhaka, it was agreed that the corridor would be opened for 24 hours for Bangladeshis in the enclave to access the mainland [9]. The corridor was officially declared open on October 19, 2011 [10].

\section{Background Of The Study}

Two gated fences and 30 meters of Indian Territory separate the Angorpota-Dohogram enclave from the main land. Prior to the grant of fulltime access permission from Indian authority through the Indian land, the residents of the enclave used to live in an abysmal conditions, with a lack of drinking water access, roads, electricity, schools and medicines. Crime was also rampant, as complaining would mean crossing the international boundary due to the lack of law enforcement resources. Residents of the enclaves are only allowed to go to their respective countries after production of an identity card and after seeking permission from the border guards, causing much resentment (FGD, 2011).

In recent times, some improvements like providing hospital facilities, development of roads and electrification are taking place in the enclaves. At the same time, the Indian corridor is now open for 24 hours 
for the easy movement of Bangladeshi exclave people. In September 2011, the governments of India and Bangladesh announced an intention to resolve the issue by means of swapping 162 enclaves, giving residents a choice of nationality [11].

The countries have moved towards an agreement to absorb the enclaves, but the resulting nationality of the current residents remains an impediment as it could have implications for border disputes in other parts of the region [12].

The present study aims to find out the socio-economic condition of the people of the exclaves in the context of changing scenario and to realize their perceptions living outside the map.

\section{Objectives Of The Study}

1) To understand the socio-economic condition of the people of Angorpota-Dohogram enclave

2) To know the availability and standard of government services in the enclave

3) To realize the present perception of the Bangladeshi enclave people regarding the exchange of enclaves between India and Bangladesh.

\section{Methodology}

In order to conduct this research both quantitative and qualitative data were collected. The quantitative data has been collected through questionnaire survey. A total 120 questionnaire containing both closed and open ended questions was surveyed following simple random sampling technique. Newspaper reports, literatures, journals were studied vigorously before finalizing the design of the questionnaire. Usually, the head of the household was taken as respondent. In cases of absent household head, the homemaker, generally a woman of that family was taken as respondent. Qualitative data were collected by keeping a diary and taking essential notes on it during the field survey. Some interviews and group discussions with local representatives and aged persons were also conducted in the study area to complete the study. The collected data were analyzed by using computer software. Secondary information used in the paper was collected from different national and international research papers, journals, articles, newspapers including internet sources.

\subsection{Socio-economic condition of the enclave people}

\section{Findings And Discussion}

\subsubsection{Educational Scenario in the enclaves}

There are three primary schools (one government primary school), a high school and a madrasha (Islamic education centre) found in Angorpota-Dohogram enclave. In this regard the area is not far behind considering its population in comparison to other areas of the country. However, the literacy rate is not satisfactory. It is found from the survey that more than $43 \%$ of the people are illiterate. It indicates that number of educational institute is less important than its other socio-economic obstacles like awareness, poverty etc. to increase the literacy rate. From the study it was found that the schools are running regularly though the number of teachers in the schools is not enough. Among the respondents only $1.8 \%$ found graduate. During FGD it was reported that a few of the inhabitants are sending their children to Panchagarh town for better education. Almost all of the participants reported that the educational scenario will soon change as the access with the mainland has been improved.

\subsubsection{Occupational Status}

The types of work through which the enclave people survive are treated as illegal by the surrounding country. That is why their economy is seen as 'criminalized economy' by the state [6]. It is somewhat different in Angorpota-Dohogram enclave. It was found from the study that maximum (72\%) people of the enclave are small or marginal farmers. The farmers mentioned that the land fertility is good and production is not bad. However, lack of irrigation facilities, high price of agricultural inputs, lack of transportation and marketing facilities are the main obstacles of agricultural development of the enclave as reported by the respondents. Again they added that, they face security problems while working in the fields which are very close to the Indian boundary. 


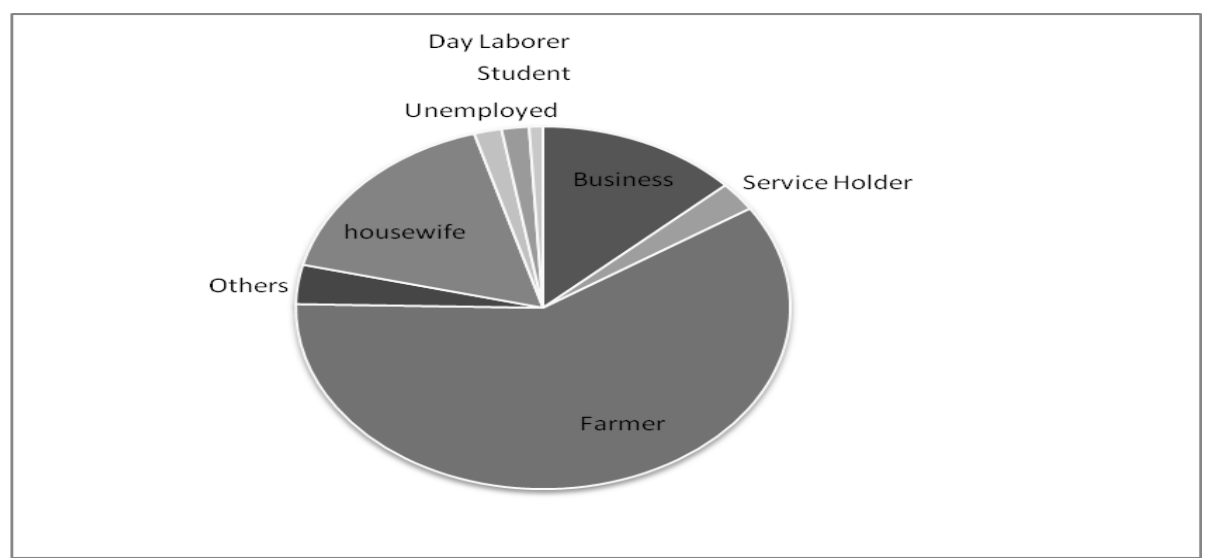

Fig. 1: Occupational status of respondents

About $20 \%$ respondents were found involved with multiple economic activities. For example, some respondents are engaged with agriculture and small business. Small business like shopkeeper, running tea stall is another means of livelihood for a small number of populations. From the interviews and FGDs with the local people it was clear that some people are engaged with cattle trading. They actually bring cows from neighboring country in an illegal way at a lower price and sell them in Bangladeshi markets with higher prices. Some Indian people around the enclave collaborate with them in this illegal business as reported by the respondents. Sometime these illegal cattle traders are arrested or shoot by the BSF (Border Security Force of India). It creates an unrest situation within these two neighboring countries. Such incidents frequency rises in those seasons when the people do not get enough income generating works to survive.

Among other occupations, driving of light vehicles like Nosimon (diesel engine driven locally made three wheelers), Tomtom (imported rechargeable battery driven three wheelers), and rickshaw are mentionable. Women are seasonally engaged with agricultural activities, rest of the time they are involved with household activities. Women involvement with formal income generating works is only $37.7 \%$, remaining $62.3 \%$ women are involved with informal sectors like household works. The practical reason behind it is that, there is limited scope of education for female and there is no formal sector where they can engage themselves.

\subsubsection{Status of Social Security}

During the study, the respondents of the enclaves expressed their satisfaction regarding the social security in recent times. Though very few (2.6\%) of them reported some incidents of physical tortures done by BSF people. But during group discussion it was mentioned by the participants that the torture of BSF people was frequent about ten years ago when the corridor was not fully opened for Bangladeshi enclave people. At that time, they have to cross the boundary to sell their products in Indian markets as illegal penetrators, which was very risky. The present scenario is much improved because the enclave dwellers can sell their products and can buy their daily essentials from Bangladeshi markets. The local people also stated that they are living in harmony and they help each other in any unexpected situation. About $37 \%$ of the respondents mentioned that they receive helps from the BGB (Border Guard Bangladesh) people to prevent crime and to tackle criminals while only $8 \%$ reported about the help receive from Police of Patgram Police Station for the same. One important findings in this regard during FGD that before electrification in the enclave in 2011, the enclave was a heaven for the criminals and different crime occurred by the out-comers in the enclave using the darkness of night and at the same time taking the chance of the slack administration. The participants also added that the enclave dwellers had to suffer much from the BGB, BSF or police hassle and the rate of such crime has reduced to a tolerance limit now-a-days.

\subsubsection{Communication facilities, availability of drinking water, sanitation status and health care services}

The only main metaled road that connected the enclave with the tin bigha corridor to the west boundary. There are few katcha roads connected with the main road. Human driven three wheeler vans, Nosimon (engine driven three wheelers) are the main transport used by the enclave people to move and to carry goods. Recently battery driven three wheelers, locally called 'Tomtom' is getting popularity to the peoples of Angorpota-Dohogram enclave. Mobile phone companies of Bangladesh have spread their coverage into the enclave. So, the isolated people can easily communicate with near and dears and other economic activities have also been expanded.

The respondent mentioned that their main sources of drinking water are tube-well (25\%), dug-well (12\%). Waters of the Tista River and local ponds are used for domestic, irrigation and other purposes than drinking. 
The respondents also added that the quality of drinking water is not apparently bad. However, arsenic presence in the groundwater has not yet been tested by any government or non-government organizations.

It was found from the study that the people of Dohogram-Angorpota are largely depending on some local healers or practitioners for general health problems. But in serious cases, they used to cross the Indian land and to face the hassle to travel to Patgram Upzila Health Complex. But prior to the fulltime opening of the Indian gates, it was not possible for all time to reach the government health care facilities of mainland in case of emergency. Health care facilities improved a great extent for the enclave people after the opening of a tenbedded government hospital in this enclave in 2011.

\subsection{Available government services in the enclave and level of satisfaction of the respondents}

About $98.2 \%$ respondents mentioned that the adult enclave dwellers have national identity card of Bangladesh. Birth and death certificates are issued by the local administration (Union Parishad). They can take part in national and local government election process. About $93.9 \%$ respondent said that the qualify people of the exclave can apply for government and non-government jobs as usual. Now, they do not face any problem to get passport from Bangladesh Government. During focus group discussion almost all of the participants expressed with deep sorry that they were deprived to avail these facilities along with other basic citizen rights because of Indian obstacles as well as lack of interests about the enclave people from the Bangladesh government. As Indian government has agreed to remain the tin bigha corridor open for 24 hours for Bangladeshi enclave people, it has become easier to reach all the citizens' facilities to them.

Very recently, electricity has enlightened the dark homes of the enclave people, crime has reduced and local administration is now aware of the people of the enclave. The people are now satisfied with road maintenance, health care and other government service facilities in comparison to the past. Still they are suffering from some problems like lack of functioning educational facilities, market, banking facilities etc.

\subsection{People's perception on enclaves exchange between India and Bangladesh}

During the present study, one of the major focuses of the questionnaire survey and Focus Group Discussion was to understand the people's pulse about the exchange of enclaves between India and Bangladesh. However, the issue of exchanging enclaves is discussed between these countries since the origin of the problem but yet to solve. One of reasons is that for the delay is that the land area of the enclaves to be exchanged is unequal [2] [13]. The total area of the enclaves that would go to Bangladesh is roughly double that which would go to India. The total area of the Indian enclaves is $69.6 \mathrm{~km} 2$ and the total area of the Bangladeshi enclaves is $49.7 \mathrm{~km} 2$. The land area that would actually be exchanged is more unequal because there are more enclaves that are Indian in Bangladesh, the large Bangladeshi enclave of Dahagram would not be transferred, and most of the counter enclaves are Bangladeshi enclaves inside Indian enclaves, which also would not be transferred [14]. During the survey, the people of Dohogram-Angorpota enclave expressed without any hesitation that they would prefer to be Bangladeshi. Rezaul Rahman, the Headmaster of Dohogram Primary School and a participant of FGD, spoke out that "We feel closer affinities for Bangladesh." At his school, pupils already consider themselves as Bangladeshi. They start schooling each day by singing the national anthem of Bangladesh together and they follow a Bangladeshi curriculum, even though students at all the schools around them follow the Indian system. Abul Kashem (65), another participant of FGD said 'I am living in Dohogram since my birth. No one knows better than me about the past and present scenario of this area. We all were agonized by Indian Police and BSF frequently. The scenario has changed just about ten years ago. At that time we had to go to Indian markets hiding our identity to sell our products like chicken, vegetables etc and to buy daily essentials like medicine, clothes etc. If the Indian Police and BSF could identify us then they brought us to the police station or BSF camp and tortured us. Even they sent the people of enclaves to jail for simple reasons. Now the situation has changed and improved. We need not to trace pass Indian border for our daily needs rather we can easily go to our mainland whenever we want for our shopping or other necessities." The participants also mentioned that the living standard and economy of Bangladesh is much better than that of India. Moreover, they feel proud to become citizens of Bangladesh and never want to be Indian.

\section{Conclusion}

Enclave problem is a political issue between the two countries. There is no alternative of resolving the problem considering the human rights and long-term relationship of both neighboring countries. Liberal foreign policy, strong political will of both countries may resolve the problem. The present study finds how life of enclave people has changed and much improved after the full time access of a small tract of land 'Tin Bigha Corridor' that is controlled by India. As Indian authority have come forward to allow the Bangladeshi enclave people to use the corridor for 24 hours, it is hoped that they should be more sincere to handover the corridor to Bangladesh as Bangladesh has already surrendered the 'Berubari' after 'Mujib-Indira Treaty 1974'. Any 
decision regarding the citizenship of the enclave people of both the countries it is very much desired that their feelings must be honored.

\section{References}

[1]. DK Illustrated Oxford Dictionary. (2003). ed. Metcalf, Jonathan \& Thompson, Della Dorling Kindersley Ltd. and Oxford University Press, UK.

[2] Whyte, B. R. (2002). 'Waiting for the esquimo: An historical and documentary study of the Cooch Behar enclaves of India and Bangladesh'. The School of Anthropology, Geography and Environmental Studies, The University of Melbourne.

[3] Whyte, B. R. (2002). 'The Cooch Behar Enclaves of India and Bangladesh: An Historical Overview and Determination of Their Number, area and Population'. Oriental Geographer. vol. 46, No. 2. Dhaka.

[4] Willem van Schendel (2002). 'Stateless in South Asia: The Making of the India-Bangladesh Enclaves'. The Journal of Asian Studies, 61, No. 1.Feb. 2002.

[5] The Daily Prothom-Alo, 18 August 2011

[6] Robbani. M Ghulam (2011) 'Chit Mahaler Manush: Rastrohinotar Etibritto'. Protichinta: a quarterly Journal on Society, Economy and State, October-December issue, 2011; Dhaka.

[7] Rabbani, M. G. (2007). 'Stateless in South Asia: Living in Bangladesh-India Enclave' in I. Ahmed (ed) Theoretical Perspectives, Centre for Alternatives, v-12 \& 13

[8] bdnews24.com, Jun 30th, 2010 and The Daily Star. November 20, 2010

[9] Bangla News 24. September 6th 2011

[10] The Daily Star, 20 October 2011

[11] AFP, 30 August 2011 \& NDTV 12 September 2011

[12] The Economist, 15 February 2011

[13] Khanna, V. (2003). Answer to unstarred question no. 3660. Indian Rajya Sabha. http://164.100.47.4/newrsquestion/ShowQn.aspx. Accessed 25.09.09.

[14] Jones, Reece (2009). 'Sovereignty and statelessness in the border enclaves of India and Bangladesh' Political Geography, ScienceDirect, vol. 28, No. 6 